\title{
Single-Setting Bilateral Hand-Assisted Laparoscopic Partial Nephrectomy
}

\author{
Rabii Madi, M.D., ${ }^{\star}$ and J. Stuart Wolf, Jr., M.D.
}

\begin{abstract}
Purpose: To assess the feasibility and safety of single-setting bilateral hand-assisted laparoscopic partial nephrectomy.

Materials and Methods: Between August 2003 and June 2004, we performed single-setting bilateral laparoscopic partial nephrectomies on three patients. A hand-assisted approach was used, employing the same handassistance incision for both sides. Renal hilar clamping was not required, as the depth of penetration of all six tumors was only 0 to $4 \mathrm{~mm}$ (mean, $1.8 \mathrm{~mm}$ ). The tumor diameters ranged from 1.8 to $3.8 \mathrm{~cm}$ (mean, $2.4 \mathrm{~cm}$ ).

Results: All operations were performed successfully, with no conversion to open surgery. Excision was performed with bipolar forceps, and final hemostasis was obtained with an argon beam coagulator (Valleylab, Boulder, CO) and Floseal (Baxter, Deerfield, IL), without suturing. The mean estimated blood loss was $208 \mathrm{~mL}$. The mean operative time was 246 minutes, which included repositioning. There were no intraoperative complications, and the postoperative course was uneventful in all patients except for a hospital stay of 5 days in one patient owing to transient ileus. Pathology revealed a benign lesion on one side and renal cell carcinoma on the other side in two patients, and bilateral leiomyomas in one patient. All margins of resection were negative, and neither of the two patients with cancer has had recurrence at a mean follow-up of 51 months. Among all three patients, the mean preoperative serum creatinine was $0.9 \mathrm{mg} / \mathrm{dL}$, and the average level at a mean of 35 months postoperatively was $1.0 \mathrm{mg} / \mathrm{dL}$.

Conclusion: Single-setting bilateral hand-assisted laparoscopic partial nephrectomies can be safely and effectively performed on patients with bilateral small exophytic kidney tumors. We do not recommend this technique if both kidneys require temporary hilar occlusion, but it can be considered if only one kidney requires hilar occlusion.
\end{abstract}

\section{Introduction}

L APAROSCOPIC RENAL SURGERY is diffusing at an increasing - rate in urologic practice. It is estimated that more than $16 \%$ of the nephrectomies are being performed laparoscopically. ${ }^{1}$ This increases to more than $70 \%$ in academic and teaching hospitals, where laparoscopic nephrectomy has became the standard of care. ${ }^{1}$ Laparoscopic partial nephrectomy is emerging as an effective and safe technique for small kidney tumors. ${ }^{2,3}$ For patients with bilateral kidney tumors staged bilateral partial nephrectomy, or radical nephrectomy on one side and partial nephrectomy on the other side, is considered the standard approach. In this report, we describe three cases of single-setting bilateral hand-assisted laparoscopic partial nephrectomy for suspected malignancy, with average followup of cases with pathologically confirmed cancer in excess of 4 years. Such an approach, in selected patients, provides excellent oncologic outcome and the advantage of a single minimally invasive procedure.

\section{Materials and Methods}

Between August 2003 and June 2004, we performed singlesetting laparoscopic partial nephrectomy in three patients. All patients presented with bilateral kidney lesions suspicious for malignancy (Table 1). Patient 1 is a 76-year-old man who presented with two enhancing solid renal masses. The tumor on the left side was on the lower pole, measuring $1.8 \mathrm{~cm}$ in greatest diameter and penetrating $3 \mathrm{~mm}$ into the kidney parenchyma (Fig. 1). On the right side, he had a $3.8 \mathrm{~cm}$ upper pole mass that penetrated $4 \mathrm{~mm}$ into the kidney parenchyma (Fig. 2). Patient 2 is a 59-year-old man who had a $2.2-\mathrm{cm}$ left lower pole enhancing renal mass and a $3.0-\mathrm{cm}$ right upper pole enhancing cystic lesion. Both lesions were very

Department of Urology, University of Michigan Health System, Ann Arbor, Michigan.

*Present affiliation: Department of Urology, University of Arkansas for Medical Sciences, Little Rock, Arkansas. 
Table 1. Preoperative Characteristics

\begin{tabular}{lcccccccc}
\hline & Age & Sex & $\begin{array}{c}\text { American Society of } \\
\text { Anesthesiologists' score }\end{array}$ & $\begin{array}{c}\text { Serum } \\
\text { creatinine }(\mathrm{mg} / \text { dL) }\end{array}$ & $\begin{array}{c}\text { Size of left } \\
\text { tumor }(\mathrm{mm})\end{array}$ & $\begin{array}{c}\text { Depth of left } \\
\text { tumor (mm) }\end{array}$ & $\begin{array}{c}\text { Size of right } \\
\text { tumor }(\mathrm{mm})\end{array}$ & $\begin{array}{c}\text { Depth of right } \\
\text { tumor }(\mathrm{mm})\end{array}$ \\
\hline Patient 1 & 76 & Male & 2 & 1.1 & 18 & 3 & 38 & 4 \\
Patient 2 & 59 & Male & 2 & 0.9 & 22 & 0 & 30 & 0 \\
Patient 3 & 55 & Female & 1 & 0.8 & 20 & 3 & 15 \\
\hline
\end{tabular}

superficial, being completely exophytic and located just on the surface of the kidney $(0 \mathrm{~mm}$ penetration). Patient 3 is a 55-year-old woman with a left lower pole tumor measuring $2.0 \mathrm{~cm}$ in diameter that penetrated $3 \mathrm{~mm}$ into the kidney as well as an enhancing mass on the right lower pole of the kidney that had a maximal diameter of $1.5 \mathrm{~cm}$ and depth of $1 \mathrm{~mm}$. All three patients were in good health, with American Society of Anesthesiologists' scores of 2, 2, and 1, respectively. All had a normal serum creatinine levels preoperatively, at $1.1,0.9$, and $0.8 \mathrm{mg} / \mathrm{dL}$, respectively. All patients had a preoperative plan of approach with hand-assisted laparoscopic partial nephrectomy without clamping the renal hilum. This retrospective data assessment was approved by our Institutional Review Board.

\section{Results}

The hand-assisted laparoscopic partial nephrectomies were successfully performed in all patients. In all cases the handassistance device was placed through the same midline incision for both sides. Of the patients, two were thin and were positioned supine with arms outstretched on an orthopedic fracture table that provided $45^{\circ}$ rotation. This allowed us to perform the partial nephrectomy on one side and then switch to the other side simply by tilting the table the other way, without requiring new sterile preparation and draping. The other patient was larger, so he was positioned in a partial flank position ( $45^{\circ}$ from horizontal, no table flexion). After finishing the first side he was repositioned in the opposite flank position, and new sterile preparation and draping was applied for the contralateral partial nephrectomy.

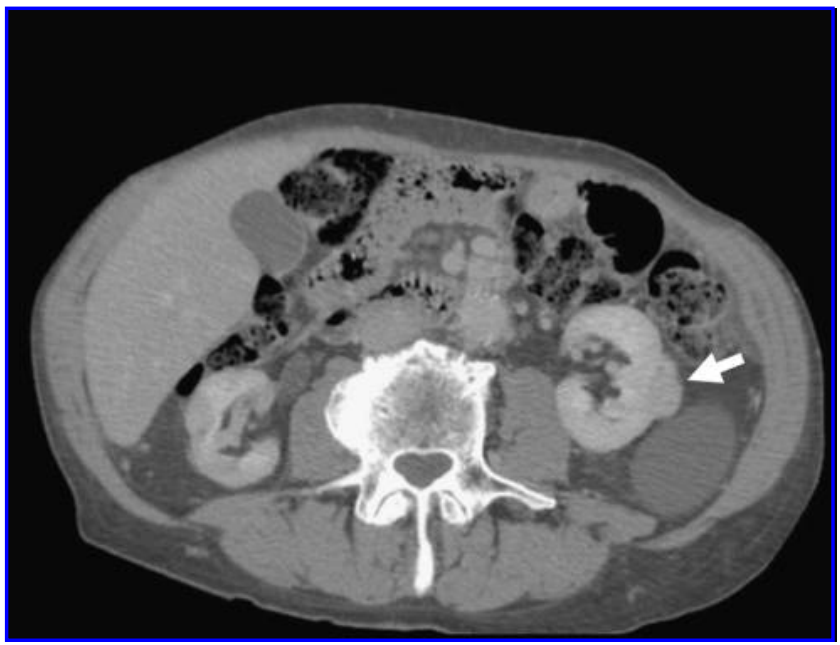

FIG. 1. Computed tomogram demonstrating left renal mass in Patient 1.
After mobilizing the kidneys and exposing the tumors, without hilar dissection, the masses were resected with bipolar forceps. Cold scissors were used as needed to cut any coagulated tissue that did not separate with the tip of the forceps. After inspecting the base of resection and taking frozen sections of any suspicious areas, we used an argon beam coagulalor (Valleylab) to fulgurate the area of resection. Floseal (Baxter) was applied over the resected area, and this was covered with a sheet of Surgicel Nu-Knit (Johnson \& Johnson Wound Management, Somerville, NJ). No clamping of the hilum was necessary because of the superficial location of the tumors. After ensuring good hemostasis at a reduced pneumoperitoneum pressure of $5 \mathrm{~mm} \mathrm{Hg}$, the cases were concluded. No drains or ureteral stents were used.

None of the patients had any intraoperative complications, and all maintained adequate urine output throughout the procedure (Table 2). The estimated blood loss averaged

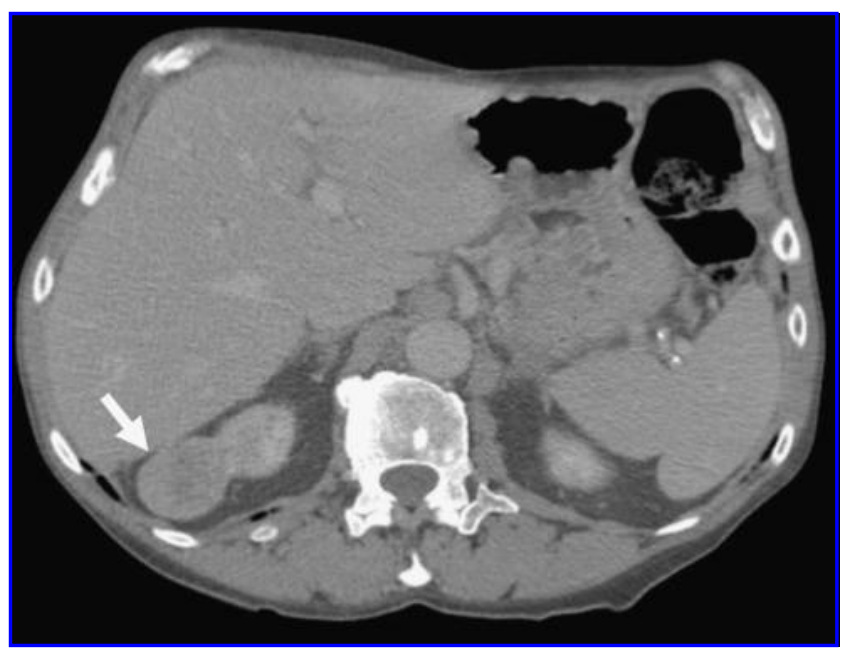

FIG. 2. Computed tomogram demonstrating right renal mass in Patient 1.

TABle 2. INTRAoperative DAtA

\begin{tabular}{lcccc}
\hline & $\begin{array}{c}\text { Estimated } \\
\text { blood loss } \\
(\mathrm{mL})\end{array}$ & $\begin{array}{c}\text { Total } \\
\text { surgery } \\
\text { time } \\
\text { (minutes) }\end{array}$ & $\begin{array}{c}\text { Serum } \\
\text { creatinine, } \\
\text { postoperative } \\
\text { day 1 }(\mathrm{mg} / \mathrm{dL})\end{array}$ & $\begin{array}{c}\text { Duration } \\
\text { of hospital } \\
\text { stay (days) }\end{array}$ \\
\hline Patient 1 & 500 & 284 & 1.5 & 5 \\
Patient 2 & 100 & 274 & 1.0 & 2 \\
Patient 3 & 25 & 180 & 1.0 & 2 \\
\hline
\end{tabular}


Table 3. Pathology and Follow-Up

\begin{tabular}{lllccc}
\hline & Pathology on the left & Pathology on the right & $\begin{array}{c}\text { Duration of radiographic } \\
\text { follow-up (months) }\end{array}$ & $\begin{array}{c}\text { Duration of creatinine } \\
\text { follow-up (months) }\end{array}$ & $\begin{array}{c}\text { Final creatinine } \\
(\mathrm{mg} / \mathrm{dL})\end{array}$ \\
\hline Patient 1 & Oncocytoma & Renal cell carcinoma & 54.5 & 54.5 & 1.3 \\
Patient 2 & Benign cyst & Renal Cell Carcinoma & 48.1 & 48.6 & 0.8 \\
Patient 3 & Leiomyoma & Leiomyoma & - & 0.6 & 1.0 \\
\hline
\end{tabular}

$208 \mathrm{~mL}$ (range, $25-500 \mathrm{~mL}$ ), and the mean operative time was 246 minutes (range, 180-284 minutes; Table 2). All patients had a slight elevation in their serum creatinine level on postoperative day 1 , with a mean increase of $0.2 \mathrm{mg} / \mathrm{dL}$ (range, $0.1-0.4 \mathrm{mg} / \mathrm{dL}$ ). The first patient stayed in the hospital for 5 days because of prolonged ileus, which resolved spontaneously. The other two patients were discharged on the second postoperative day.

All patients had negative margins on final pathology (Table 3). Pathology revealed a benign lesion on one side and renal cell carcinoma on the other side in two patients, and bilateral benign leiomyomas in one patient. Of the two patients with cancer, radiographic surveillance with chest radiography and computed tomography has continued for 55 and 48 months (mean, 51 months), with no evidence of recurrence. A serum creatinine is available a mean of 35 months postoperatively (range, $0.6-55$ months) in the three patients, with a mean increase of $0.1 \mathrm{mg} / \mathrm{dL}$ (range, $-0.1-0.2 \mathrm{mg} / \mathrm{dL}$ ).

\section{Discussion}

Bilateral laparoscopic nephrectomy has been reported mostly for autosomal dominant polycystic kidney disease. ${ }^{4-6}$ It has also been demonstrated to be safe in settings such as nonfunctioning kidneys and malignant acquired cystic disease in patients with end-stage renal disease. ${ }^{7}$ Reisiger et $\mathrm{al}^{8}$ described Washington University's experience with singlesetting bilateral kidney surgery. Among the 13 cases reported, only one was a bilateral partial nephrectomy. Our small series includes three successful cases of single-setting bilateral laparoscopic partial nephrectomy for kidney tumors.

All three procedures were performed with hand-assisted laparoscopy. The same hand incision was used to reach both kidneys. Resection was with bipolar forceps. Our approach to partial nephrectomy has changed in the years since these procedures were performed. ${ }^{3}$ First of all, for accessible tumors we now use standard laparoscopy (transperitoneal or retroperitoneal, depending on location), reserving hand-assistance for tumors that are located such that manipulating the kidney with an intraabdominal hand is helpful in accessing the operative site (primarily large upper pole masses). Second, we no longer resect shallow tumors with coagulation devices; instead, we use cold scissors to resect the mass and then achieve hemostasis after resection. Blood loss, for shallow tumors, is acceptable, and the margins at resection are better defined with this technique.

We did not notice any adverse outcomes that may be related to prolonged operative time, or operating on and manipulating both kidneys at the same time. The excellent longterm renal function confirms the safety of this approach. The financial, psychological, and cosmetic advantages of a single rather than staged approach are self-evident. These benefits noted, it then should be emphasized that our patients were carefully selected. All patients were healthy with normal serum creatinine levels. In addition, the tumors were small and superficial. The tumor's location, size, and depth of penetration into renal parenchyma are important factors when considering nephron sparing surgery. Our group has demonstrated that it is safe to avoid clamping of the hilum for tumors penetrating less than $5 \mathrm{~mm}$ into the renal parenchyma. ${ }^{3}$ We do not advocate this approach for deeper tumors for which clamping the hilum of both kidneys may be necessary, as this may put the patient at unnecessary risk of acute renal failure, although the bilateral single-setting approach could be considered if renal hilar clamping is necessary on only one side.

In summary, bilateral single-setting laparoscopic renal surgery is reasonable for the management of some bilateral renal lesions for which surgical intervention is indicated. The technique saves the patient an additional operation, with no increased risk of complications in selected patients. This approach might be used for solid lesions for which excision or ablation is required, and might also be considered in cases of cystic lesions for which exploration (with excision as indicated by intraoperative findings) is intended. We used a handassisted approach, but if the tumors are easily accessible then a standard transperitoneal or retroperitoneal approach can be used. Bilateral single-setting laparoscopic renal surgery should be avoided if the renal hilum of both kidneys needs to be occluded, but can still be employed if only one kidney requires hilar occlusion.

\section{Disclosure Statement}

No competing financial interests exist.

\section{References}

1. Miller DC, Taub DA, Dunn RL, et al. Laparoscopy for renal cell carcinoma: Diffusion versus regionalization? J Urol 2006; 176:1102-1106.

2. Gill IS, Matin SF, Desai MM, et al. Comparative analysis of laparoscopic versus open partial nephrectomy for renal tumors in 200 patients. J Urol 2003;170:64-68.

3. Weizer AZ, Gilbert SM, Roberts WW, et al. Tailoring technique of laparoscopic partial nephrectomy to tumor characteristics. J Urol 2008;180:1273-1278.

4. Rehman J, Landman J, Andreoni C, et al. Laparoscopic bilateral hand assisted nephrectomy for autosomal dominant polycystic kidney disease: Initial experience. I Urol 2001; 166:42-47.

5. Gill IS, Kaouk JH, Hobart MG, et al. Laparoscopic bilateral synchronous nephrectomy for autosomal dominant polycystic kidney disease: The initial experience. J Urol 2001; 165:1093-1098.

6. Jenkins MA, Crane JJ, Munch LC. Bilateral hand-assisted laparoscopic nephrectomy for autosomal dominant polycystic 
kidney disease using a single midline HandPort incision. Urology 2002;59:32-36.

7. Ghasemian SR, Pedraza R, Sasaki TA, et al. Bilateral laparoscopic radical nephrectomy for renal tumors in patients with acquired cystic kidney disease. I Laparoendosc Adv Surg Tech A 2005;15:606-610.

8. Reisiger K, Tran V, Figenshau RS, et al. Single-setting bilateral laparoscopic renal surgery: Assessment of single-stage procedure. Urology 2005;65:892-897.
Address reprint requests to: J. Stuart Wolf, Jr., M.D. Department of Urology University of Michigan Health System 1500 East Medical Center Drive

TC 3875

Ann Arbor, MI 48109-5330

E-mail:wolfs@umich.edu 
This article has been cited by:

1. Rabii Madi. 2009. Single-setting robotic radical nephrectomy and radical prostatectomy. Journal of Robotic Surgery 3:3, 195-198. [CrossRef] 